\title{
How to Cultivate the Ability of Innovative Thinking In Computer Programming Teaching
}

\author{
Fuqian Shi \\ Institute of Hospital Management, Wenzhou Medical College \\ PO box 325035, Wenzhou 325000, China \\ Tel: 086-577-86689913 E-mail:sfq@wzmc.net \\ Jincai Wei \\ Institute of Hospital Management, Wenzhou Medical College \\ PO box 325035, Wenzhou 325000, China \\ Tel: 86-577-86699348_E-mail:prcctv@hotmail.com
}

The research is financed by High Education Reform Project of Wenzhou Medical College, 2007.

\begin{abstract}
In the current teaching activities on curriculum, teachers taught all kinds of computer language at the most of the time. Students also focus on a variety of examinations, but the real time to train students' independent software developing skill is very limited. This has resulted in the students only to copy other people's systems design ideas, materials or other software reproduction procedures and take a simple so-called "Program Design." Based on this, this paper introduced a variety of computer teaching activities in classroom and formed role for training students' imagination, the ability to find and explore, knowledge transfer capability and the quality of innovative thinking of students.
\end{abstract}

Keywords: Independent thinking, Innovative education, Computer programming teaching

How to cope with popular education needs of the situation and train high-quality creative talents is a tough problem currently in the higher education reform process. High-quality creative talent's cultivation is the main object of education. The popularization of education is the current status and the direction of Chinese higher education. Classroom teaching was regard as the main form of higher education personnel training; how to deal with this contradiction? Combining with many years of experience in teaching computer programming, we summed up the following aspects:

In the computer-programming process, it often needs to choice and judge numerous and various complex events, then to classify and rank, and to achieve its work in a variety of applications demand by using the computer language in practice; therefore, in training teaching students, critical thinking ability is the core. But in the cultivation of thinking ability, the ability to cultivate innovative thinking has a unique value. Here, we must be clear, students' cultivate innovative thinking is the ability to develop their sense of innovation and ability to innovate, innovative spirit and habits, not to require students as scientists, inventors, like the number of inventions and creations. Thus, the teaching of computer software programming should not be built on the thinking of teachers or teaching materials on the basis of the authors, and students should be established to start thinking of the classroom structure model. "Study to thinking, study to innovating" as the purpose of thinking innovative classroom structure would focus on the training of thinking ability.

In order to enable students in time and energy on possible in accordance with their own characteristics to develop ourselves, in teaching management, first of all, teaching the basic requirements should be adjusted in order to meet the needs of innovative personnel training, and not a single test scores. Basic requirements of many courses were enacted in the early 1990s. On the one hand, the examination results are everything; on the other hand, this stage is still in the elite stages of education, and would be higher requirement. In the stage of popular education, certain requirements are difficult to achieve for some students. In such a request, some students exhausted their energy and time and still could not meet the requirement; students not only do not have the time and energy to play, develop their own skills, but their interest and confidence in learning are destroyed. So instead, why not reduce the number of requirements in computer programming teaching activities? 


\section{Creating a learning environment which is more relaxed, harmonious and self-sufficient in student performance}

In the process of teaching, teachers love to endless land to educate students on off-the-shelf materials in various languages orders and grammatical rules, and further point out that what is the focus of the examination. Students have little autonomy and the opportunity to participate in teaching activities in accordance with their own choice of study and interest in the content. Soon, their enthusiasm disappeared, and self-confidence lacked. Learning has become a focus for the examination of the contents and mechanical memory. Thinking ability is de-gradated, and creative potentials are mercilessly stifled. Teachers teach hard, students learn fidgety, and even the scope of the examination will not be good results.

Renowned psychologist E. P. Torrance said that if we are to create creativity, we need to provide a friendly and encouraging environment in which to make the prosperity and development. Clearly, a relaxed and harmonious, creative context is to train students to create an important condition for thinking. Therefore, in the process of teaching programming, teachers dare let go, to give the independent learning opportunities for students and to enhance students' self-confidence, encouraging them to use computer language to realize their ideas, their creative thinking to provide a relaxed environment. In classroom teaching, I deal with this: First, change the serious classroom atmosphere, create a relaxed, natural atmosphere, and encourage students to give question to teacher. The more novel issues unique knowledge, the more the better. If teachers didn't resolve it, this is the greatest honor of students. Gradually, students interested in a challenge and confidence stronger. Then, encourage students to question each other, and each completion of a module, conduct a program design contest. Program design of a content-based modular, but not limited to units, not confined to the after-school textbook exercises. Let us see who will design the most creative, original or whether teachers have the final say, but to enable students to democratic evaluation, selection of the winners and record results, when appropriate conditions to encourage. These measures aroused the students learning initiative. In order to design a good program, they will not only seriously reading materials content, but also access to a large number of extra-curricular literature, increasingly keen interest in learning. The potential for better students, the ability to enable him to be further improved, I used student-teaching method, teachers lead students to mobilize awareness of the main roles, and guide students in how to learn, how to teach, after prep, voluntary enrollment of students and teachers under the guidance of lesson preparation. Part of the trial, after a period of training, the analysis found that students learning ability and enthusiasm really improve a lot. Sometimes, the students I was teaching design on unexpected.

\section{Encourage students to a variety of perspectives, levels, areas to explore and train the students' practical ability}

In the culture of innovative thinking, we should minimize a variety of restrictions, and sometimes it needs "contempt" so-called answers. To foster their innovative thinking, the answer is absolutely not the most important; the most important thing is whether students' thinking space is expanded and opened up; whether to find out the answer from a variety of perspectives and a variety of levels; whether a variety of areas of interest is excited up; Whether multi-dimensional thinking capacity -- extremely important innovative education is trained. The design of opening problems such as "One question more answer" is the basis of this mode of training. A result with a variety of programming languages to achieve; a system structure and expand a number of application areas; such training is the key. This is very conducive to culture the students' creative thinking and innovative capability. It need to encourage and cultivate students at unconventional thinking, the answer is not limited to materials and also not restricted to teachers thinking. Unconventional thinking is very important for training students' creative ability, no "Unconventional thinking" has not "innovation." But in the classroom teaching, many teachers often overlooked unconventional thinking training; and even a subtle blow to the students the desire to unconventional thinking. This should not be happened. In order to encourage students' unconventional thinking, we need to take fully affirmed to students even it is a not very good design

At present, many computer curriculums were designed a large number of exercises and materials after school, the teacher also operate many homework under circumstances. But these exercises and operations are basically the so-called "standard answer"; the students will imitate materials, and generally get a high score; so students will only lead to rote. Teaching management department ask teachers to provide a uniform standard answer, and not to allow students for innovative attempt, they do not tolerate mistakes or failures; this stifles students' innovative capacity seriously and cure their brain. Therefore, students should not be satisfied to mention a unified learning methods and standard answer. For homework arrangement, it should be arranged none standard answer; this will enable students to give full play to creative capacity, and make our own operations in a variety of capacity and train the students' independent thinking ability and operation by hands.

\section{Foster students to discovery problem and suspect them}

Learning comes from thinking, thinking comes from question". In classroom teaching, there is no thinking without question; also there is no learning without thinking. Therefore, the classroom should first become a venue for students to question various things. On the basis of learning various ready-made conditions, we need to point out its design flaws, 
suspect its design ideas and concepts and think to improve and refine the program. This should become the direction of computer programming teaching. And as teachers, we should create a wide range of issues situations for students and train the students' innovative thinking ability. Therefore, teachers should have a strong awareness of the problem; cleverly seize the key steps of computer language or procedures. In the core modules, the creation of the problem would be situated to the students, inspire students to think and encourage students to question, even if the problem naïve. It is all right. Perhaps this is the start of independent thinking innovation for students. Such teaching activities in the process, we will discover that different students have different problems. We can show these issues on discussing. Most cases would be discussed very keen because there has not psychological fear between students not like students and teachers. Teachers need to encourage the parties to take such thinking. This opened the students thinking and inspired the students' innovative thinking.

"Doubts-problem-innovation" is a necessary way of creative thinking. Discovering issues and raising questions are the main hallmark of a person with creative potentials.

\section{The key of the innovative thinking is to develop students' imagination ability}

Innovative thinking is a thinking quality built on the innovative spirit. The key of software "innovation" is to create the procedures of currently no exist structural design and ideas, which requires imagination. The thinking of software designer is inseparable from imagination. The imaginative thinking in programming is incomparable. It is no exaggeration to say that no such imagination, there is no current computer software industry. Imagination is the driving force of the computer software, which is the soul of computer to constantly enter behind the area of daily life. Aristotle once said: "Imagination is the discovery, invention activities of the source of all creation." No imagine, no create. No the rich imagination, the variety of computer software programming language has become the most boring. Faced with such a heap of symbols, not imagined, students will not only difficult to understand its contents, but hard to develop thinking ability; While students are the main characteristics of the image of the thinking. Efforts to cultivate and inspire their imagination, is a magic weapon to foster their ability to innovate. Faced with the rapid development of computers, it has been said: the computer, not impossible, only unexpected. From a point of this view, the cultivation of innovative thinking of computer software talents is the key to the cultivation of imagination.

In the process of teaching, we must be bold to train students' imagination; pay attention to capture those students which think fast and have strong curiosity; to protect their curiosity, imagination, and guide them to positive thinking; to take much multi-direction, communicating exploring and pondering between the students and teachers; protect the seeds of their sense of innovation; inspire students through analysis, judgment, summarized and integrated so that they are fully divergent thinking of expression to have constant discoveries and innovations. At the same time, it should be paid to guide these "can think" students "can do", to improve their practical ability; and thereby facilitate the continuous development of creative thinking. Training through divergent thinking will improve students' fluent, flexible and innovative thinking.

In today's world, fierce competition calls for diversification thinking and creative talent. Innovative thinking of independent thinking, challenging and to pursuit the truth are the mainstream in IT industry. Nathan Marsh Puse, Harvard University president y, believes that "whether a person with innovative thinking is the watershed between first-class professionals and third-rate talent." Innovation is the focus of quality education; education need for innovation. In the process on teaching computer programming courses, we need to cultivate and foster the computer software talent be much more innovative, train students to create awareness of the importance of thinking and possibilities and create a environment which suit their own interests, hobbies, talent and personality development, so that they can have the enough competition in the information age, victory by thinking, victory by innovation.

\section{References}

Clifton F. Conrad, Jason Johnson and Divya Malik Gupta. (2007). Teaching-for-Learning (TFL): A Model for Faculty to Advance Student Learning. Innovative Higher Education. Volume 32, Number 3, 153-165.

David F. Treagust. (2007). Research-based Innovative Units for Enhancing Student Cognitive Outcomes and Interest in Science. Roser Pintó, Digna Couso (Eds), Contributions from Science Education Research. Springer Netherlands, pp.11-26.

Gary D. Koppenhaver, Virginia L. Blackburn, Kay M. Palan, Sue Ravenscroft and Charles B. Shrader. (2007). Student/Faculty Connections in the Development of Teaching, Decision Sciences Journal of Innovative Education Vol. 5 Issue 2, 375.

Guijuan Gao. (2002). The Self-Taught Higher Education Examination in China: As Manifested in the Educational Service and National Examination. Educational Research for Policy and Practice Volume 1, Numbers 1, 99-112. 
Nandasara S.T., Samaranayake V. K. and Yoshiki Mikami. (2006). Revolutionary Development of Computer Education - A Success Story. IFIP International Federation for Information Processing- History of Computing and Education 2 (HCE2). Volume 215, 167-180.

Noel watts. (2007). Innovative Second and Foreign Language Education in the South Pacific. In Nancy H. Hornberger (Eds). Encyclopedia of Language and Education, Springer US, pp.1350-1361.

Thomas F., Patterson Jr. (2007). The Rise and Fall of Innovative Education: An Australian University Case Study. Innovative Higher Education. Volume 32, Number 2, 71-84. 